\title{
PENGEMBANGAN MEDIA SMART TRIGO UNTUK PEMBELAJARAN TRIGONOMETRI
}

\author{
Anis Novika Utami ${ }^{1}$, Helti Lygia Mampouw ${ }^{2}$ \\ ${ }^{1,2}$ Universitas Kristen Satya Wacana, Jl. Diponegoro 52-60, Salatiga \\ 202016027@student.uksw.edu
}

\begin{abstract}
In learning often using textbooks as study resources. Learning media help students to more clearly accept the material presented. This research aims to describe the development of Smart Trigo as a result of the innovation of trigonometric learning media. This development research applies the stages of Analysis, Design, Development, Implementation, Evaluation. Smart Trigo is a trigonometric learning media that is packaged in the form of an AutoPlay Media Studio 8 based game has been validated by experts, practitioners and students. Smart Trigo contains material trigonometric ratios, sine cosine rules, and graphs of trigonometric functions. Smart Trigo was developed based on analysis of student needs, analysis of material on the curriculum, and analysis of the infrastructure availability. The product trial show that Smart Trigo can improve trigonometric learning because students are motivated and can focus on the use of Smart Trigo. Smart Trigo is effective because learning becomes fun, the media is interesting, friendly to use and helps student to understanding trigonometry concepts.
\end{abstract}

Keywords: Smart Trigo, ADDIE, Trigonometry

\begin{abstract}
Abstrak
Dalam pembelajaran seringkali menggunakan buku paket sebagai sumber belajar. Media pembelajaran membantu siswa agar lebih jelas menerima materi yang disampaikan. Penelitian ini bertujuan untuk mendeskripsikan pengembangan Smart Trigo sebagai hasil inovasi media pembelajaran trigonometri bagi siswa kelas X SMK. Penelitian pengembangan ini menerapkan tahapan Analysis, Design, Development, Implementation, Evaluation. Smart Trigo adalah media pembelajaran trigonometri yang dikemas dalam bentuk permainan berbasis AutoPlay Media Studio 8 yang telah divalidasi oleh ahli, praktisi maupun siswa. Smart Trigo memuat materi rasio trigonometri, aturan sinus kosinus, dan grafik fungsi trigonometri. Smart Trigo dikembangkan berdasarkan analisis kebutuhan siswa, analisis materi pada kurikulum, dan analisis ketersediaan sarana prasarana. Hasil ujicoba pada siswa kelas X SMK menunjukkan Smart Trigo memotivasi siswa karena dapat meningkatkan hasil belajar trigonometri karena siswa termotivasi dan dapat memusatkan perhatian pada penggunaan Smart Trigo. Smart Trigo juga efektif karena pembelajaran menjadi menyenangkan, media menarik, ramah digunakan dan membantu memahami konsep pada trigonometri.
\end{abstract}

Kata kunci: Smart Trigo, ADDIE, Trigonometri

\section{PENDAHULUAN}

Revolusi industri 4.0 di bidang pendidikan mendorong guru untuk memanfaatkan teknologi informasi dalam pembelajaran. Kemajuan suatu negara tergantung pada tiga faktor yaitu pendidikan, kualitas intuisi dan ketersediaan infrastruktur. Dunia pendidikan dituntut untuk mengikuti perkembangan teknologi yang sedang berkembang sebagai fasilitas untuk memperlancar proses pembelajaran. Permendiknas No 16 tahun 2007 mengenai Standar Kualifikasi Akademik dan Kompetensi Guru, Kompetensi Pedagogik guru SMA/SMK menyatakan bahwa guru harus memanfaatkan teknologi informasi dan komunikasi untuk pembelajaran. Di era globalisasi, penggunaan media berbasis IT menjadi sebuah kebutuhan dan tuntutan. Kemajuan teknologi berkembang sangat pesat. Salah satu kemajuan teknologi adalah komputer. Komputer banyak digunakan oleh masyarakat dalam membantu pekerjaan, salah satunya di bidang pendidikan. Di bidang pendidikan, komputer memegang peranan penting, hampir semua kegiatan di bidang 
pendidikan menggunakan komputer, contohnya surat menyurat, mengolah nilai, pembuatan perangkat pembelajaran. Namun sebagian besar sekolah memanfaatkan komputer sebagai alat bantu administrasi sekolah. Penggunaan komputer sebagai media pembelajaran masih minim. Hal itu dikarenakan minimnya pengetahuan guru tentang bagaimana cara mengembangkan media yang berbasis komputer dan keterbatasan kemampuan untuk mengembangkan media berbasis komputer.

Guru dan peserta didik selalu terlibat dalam pembelajaran. Interaksi guru dan siswa tidak hanya dengan bertatap muka tetap dapat menggunakan media telepon, komputer, internet, email, dan lain-lain. Guru dapat memberikan layanan tanpa bertatap muka dengan siswa. Guru memegang peranan sangat penting dalam pembelajaran karena sebagai pengajar atau penyampai materi ajar, sedangkan peserta didik sebagai perespon. Dalam menyampaikan materi ajar, strategi dan media pembelajaran ditawarkan kepada guru agar dimanfaatkan untuk pembelajaran. Permasalahan yang biasanya terjadi dalam pembelajaran adalah kurang menariknya media pembelajaran yang digunakan dan kurangnya motivasi peserta didik dalam pembelajaran. Media pembelajaran merupakan teknologi yang dimanfaatkan untuk pembelajaran (Azhar, 2016). Media pembelajaran memiliki dua peranan penting dalam proses pembelajaran, pertama media sebagai alat bantu mengajar, karena setiap materi ajar memiliki tingkat kesukaran yang bervariasi. Tanpa bantuan media, materi ajar akan sukar dipahami oleh siswa. Kedua, media sebagai sumber belajar yang diinginkan sendiri oleh siswa secara mandiri. Media pembelajaran sebagai salah satu sumber belajar, ikut membantu guru dalam memudahkan tercapainya pemahaman materi ajar oleh siswa (Rusman, 2012).

Dalam peningkatan mutu pembelajaran, komputer dapat dimanfaatkan dalam dua macam penerapan yaitu dalam bentuk pembelajaran dengan komputer atau Computer Assited Instruction (CAI) dan pembelajaran berbasis komputer atau Computer Based Instruction (CBI) (Rusman, 2013). Pembelajaran menggunakan komputer lebih dominan dalam meningkatkan kualitas pembelajaran sebagai alat bantu presentasi. AutoPlay Media Studio merupakan salah satu aplikasi bebas akses yang dapat digunakan untuk menciptakan media pembelajaran yang menarik, aplikasi ini juga tergolong aplikasi yang mudah dioperasikan karena tidak menggunakan bahasa pemrograman yang rumit. Aplikasi ini juga dapat diakses oleh siapapun dan tidak dipungut biaya. Aplikasi ini bisa menggabungkan tulisan, video, animasi, gambar dan suara.

Media pembelajaran AutoPlay Media Studio sudah digunakan secara luas dalam matematika. Wandani menemukan hasil belajar pada evaluasi satu lawan satu dengan presentase ketuntasan 100\%, hasil belajar pada evaluasi kelompok kecil dengan presentase ketuntasan 90\%, dan hasil belajar pada evaluasi lapangan dengan presentase ketuntasan 93,75\%. Utami \& Mampouw menemukan media AlSmart memotivasi siswa sebesar 95\%, kemudahan penggunaan sebesar 90\% dan membantu siswa dalam pembelajaran sebesar 96,67\%, sehingga Al-Smart dapat digunakan sebagai media pembelajaran interaktif.

Setiap pelaksanaan pembelajaran, guru diharapkan dapat memilih metode dan media pembelajaran yang menarik untuk meningkatkan motivasi siswa dalam belajar, terlebih dalam 
pembelajaran matematika. Matematika merupakan pembelajaran yang wajib diajarkan ditingkat pendidikan SD, SMP, dan SMA/SMK. Matematika berguna untuk memecahkan masalah dalam kehidupan sehari-hari. Namun tidak sedikit peserta didik yang menganggap matematika adalah pelajaran yang sulit, salah satunya dalam materi trigonometri. Trigonometri merupakan mata pelajaran yang diajarkan di SMA/SMK. Trigonometri merupakan salah satu cabang matematika yang mempelajari tentang segitiga, fungsi-fungsi trigonometri seperti sinus, kosinus, tangen, kosekan, sekan dan kotangen serta penerapannya dalam luas segitiga. Trigonometri merupakan materi ajar yang menduduki peringkat atas kesulitan guru dalam pengelolaan pembelajaran (Sultoni, 2018).

Berdasarkan hasil wawancara dengan guru matematika SMK dan siswa, siswa mengalami kesulitan dalam pemahaman trigonometri karena rendahnya motivasi siswa mengikuti pembelajaran trigonometri dan belum ada media pembelajaran yang sesuai. Daya serap trigonometri siswa SMA/SMK masih tergolong rendah. Data Ujian Nasional tahun ajaran 2018/2019 materi geometri dan trigonometri sebesar 36,77. Hal tersebut ditunjukkan pada Tabel 1.

\section{Tabel 1.}

Presentase siswa SMA yang menjawab benar tingkat Nasional

\begin{tabular}{|c|l|c|c|}
\hline \multirow{2}{*}{ No } & \multicolumn{1}{|c|}{ Materi yang Diuji } & \multicolumn{2}{|c|}{ Tahun Pelajaran } \\
\cline { 3 - 4 } & & $\mathbf{2 0 1 7 / 2 0 1 8}$ & $\mathbf{2 0 1 8 / 2 0 1 9}$ \\
\hline 1 & Aljabar & 37,04 & 38,63 \\
\hline 2 & Geometri dan Trigonometri & 33,79 & 36,77 \\
\hline 3 & Statistika & 31,10 & 36,88 \\
\hline
\end{tabular}

Diadaptasi dari Kemendikbud, 2019 (http://hasilun.puspendik.kemdikbud.go.id)

Pada materi trigonometri, terdapat indikator yang memiliki daya serap di bawah 55\%. Hal tersebut ditunjukkan pada Tabel 2.

\section{Tabel 2.}

Indikator yang diuji yang memiliki presentase di bawah 55\%

\begin{tabular}{|c|l|c|}
\hline No & \multicolumn{1}{|c|}{ Indikator yang Diuji } & Presentase \\
\hline 1 & $\begin{array}{l}\text { Menentukan nilai sin, cos atau tan jika diketahui nilai perbandingan } \\
\text { trigonometri }\end{array}$ & 35,28 \\
\hline 2 & $\begin{array}{l}\text { Menentukan salah satu panjang sisi dari segitiga siku-siku jika diketahui salah } \\
\text { satu nilai perbandingan trigonometrinya }\end{array}$ & 26,92 \\
\hline 3 & $\begin{array}{l}\text { Menyelesaikan permasalahan dalam dunia nyata yang berkaitan dengan } \\
\text { perbandingan trigonometri }\end{array}$ & 18,89 \\
\hline 4 & Menentukan himpunan penyelesaian dari persamaan trigonometri & 17,21 \\
\hline
\end{tabular}

Diadaptasi dari Kemendikbud, 2019 (http://hasilun.puspendik.kemdikbud.go.id)

Media pembelajaran diharapkan dapat memotivasi peserta didik dalam belajar matematika dan dapat membantu menciptakan pembelajaran yang kondusif. Dengan media pembelajaran Smart Trigo, diharapkan peserta didik lebih antusias dan lebih aktif dalam pembelajaran matematika khususnya untuk materi trigonometri. 
Tujuan penelitian ini adalah mendeskripsikan pengembangan media Smart Trigo untuk pembelajaran trigonometri kelas $\mathrm{X}$.

\section{METODE}

Jenis penelitian ini adalah pengembangan dengan model Analisis (Analysis), Desain (Design), Pengembangan (Development), Implementasi (Implementation), Evaluasi (Evaluation). ADDIE pertama kali dikenalkan oleh Reiser dan Mollenda pada tahun 1990-an. Model ini dikembangkan lagi oleh Dick and Carry (1996) dalam merancang sistem pembelajaran. Tahapan ADDIE adalah sebagai berikut:

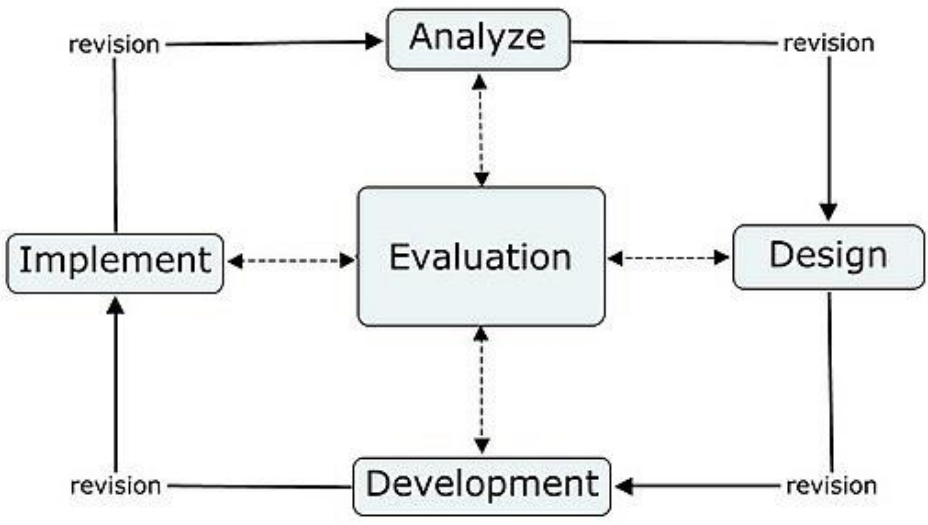

Gambar 1. Tahapan ADDIE

Produk yang dihasilkan adalah media pembelajaran Smart Trigo untuk siswa kelas X SMK. Smart Trigo berisi materi trigonometri kelas X. Materi yang terdapat dalam media pembelajaran ini meliputi perbandingan trigonometri pada segitiga siku-siku, identitas trigonometri, nilai fungsi trigonometri dalam sudut istimewa, fungsi trigonometri di berbagai kuadran, dan grafik fungsi trigonometri.

Smart Trigo dibuat menggunakan aplikasi AutoPlay Media Studio. Aplikasi ini merupakan aplikasi bebas akses dan tidak dipungut biaya. Aplikasi AutoPlay Media Studio dapat menggabungkan tulisan, video, animasi, gambar dan suara, tidak menggunakan bahasa pemrograman yang rumit, dan dapat dijalankan di Windows 7, Windows 8, Windows 10 dan Windows XP.

Smart Trigo merupakan sebuah aplikasi yang berisi tentang pembelajaran trigonometri kelas $\mathrm{X}$ dan terdapat latihan soal berupa kuis sebagai bentuk evaluasi siswa. Materi trigonometri yang terdiri dari rasio trigonometri, aturan sinus kosinus dan grafik fungsi trigonometri. Rasio trigonometri meliputi perbandingan trigonometri dalam segitiga siku-siku, identitas trigonometri, nilai fungsi trigonometri dalam sudut istimewa dan fungsi trigonometri di berbagai kuadran. Grafik fungsi trigonometri meliputi cara menggambar grafik fungsi sinus, kosinus dan tangen berdasarkan bantuan tabel untuk menentukan titik koordinat. 


\section{HASIL}

\section{Tahap Analisis}

Terdapat 3 pertimbangan utama dalam melakukan analisis yaitu analisis kebutuhan siswa, analisis materi pada kurikulum, dan analisis sarana prasarana. Analisis kebutuhan siswa yang dilakukan terhadap siswa kelas X SMK dapat disimpulkan bahwa: sebagian besar peserta didik mengalami kesulitan dalam pembelajaran matematika khususnya materi trigonometri. Hal tersebut ditinjau dari daya serap Ujian Nasional tahun ajaran 2018/2019 tingkat SMA/SMK se-kota Salatiga.

\section{Tabel 3.}

Presentase siswa menjawab benar pada Ujian Nasional tahun ajaran 2018/2019 Kota Salatiga

\begin{tabular}{|l|l|c|c|c|c|}
\hline \multirow{2}{*}{ No } & \multicolumn{2}{|c|}{ Materi yang Diuji } & \multicolumn{4}{|c|}{ Presentase } \\
\cline { 3 - 6 } & & $\begin{array}{c}\text { SMA } \\
\text { (IPA) }\end{array}$ & $\begin{array}{c}\text { SMA } \\
\text { (IPS) }\end{array}$ & $\begin{array}{c}\text { SMA } \\
\text { (BAHASA) }\end{array}$ & SMK \\
\hline 1 & Aljabar & 67,59 & 60,64 & 64,36 & 56,12 \\
\hline 2 & Kalkulus & 59,15 & 46,89 & & 38,61 \\
\hline 3 & Geometri dan Trigonometri & 54,77 & 40,08 & 51,85 & 39,81 \\
\hline 4 & Statistika & 57,08 & 57,66 & 52,87 & 54,96 \\
\hline
\end{tabular}

Diadaptasi dari Kemendikbud, 2019 (http://hasilun.puspendik.kemdikbud.go.id)

Pada Tabel 3 terdapat presentase siswa menjawab benar dalam mengerjakan ujian nasional. Pada materi trigonometri, presentase dibawah kriteria pencapaian kelulusan yaitu 55 dari skala 0-100. Dapat disimpulkan bahwa materi trigonometri merupakan materi yang sulit. Terdapat indikator materi yang mempunyai presentase di bawah 55 yang ditunjukkan pada Tabel 4.

\section{Tabel 4.}

Indikator yang diuji yang memiliki presentase dibawah 55

\begin{tabular}{|l|l|c|}
\hline No & \multicolumn{1}{|c|}{ Indikator yang Diuji } & Presentase \\
\hline 1 & Menentukan nilai suatu perbandingan trigonometri di berbagai kuadran & 43,81 \\
\hline 2 & $\begin{array}{l}\text { Menentukan nilai perbandingan trigonometri suatu sudut pada segitiga apabila } \\
\text { perbandingan trigonometri salah satu sudut diketahui }\end{array}$ & 46,35 \\
\hline 3 & $\begin{array}{l}\text { Menentukan salah satu panjang sisi dari segitiga siku-siku jika diketahui salah } \\
\text { satu nilai perbandingan trigonometrinya }\end{array}$ & 27,09 \\
\hline 4 & $\begin{array}{l}\text { Menyelesaikan permasalahan dunia nyata yang berkaitan dengan perbandingan } \\
\text { trigonometri }\end{array}$ & 22,92 \\
\hline 5 & Menentukan himpunan penyelesaian dari persamaan trigonometri & 16,67 \\
\hline
\end{tabular}

Diadaptasi dari Kemendikbud, 2019 (http://hasilun.puspendik.kemdikbud.go.id)

Analisis materi pada kurikulum yang telah dilakukan, menelaah Permendikbud Tahun 2016 Nomor 24 menyatakan bahwa materi trigonometri diajarkan di kelas X, XI, dan XII. Di kelas X, trigonometri diajarkan di semester 2, kelas XI diajarkan di semester 1, dan kelas XII diajarkan di semester 2. Kompetensi dasar pada materi trigonometri kelas X disajikan pada Tabel 5. 


\section{Tabel 5.}

Kompetensi Dasar Pengetahuan dan Kompetensi Dasar Keterampilan materi trigonometri

\begin{tabular}{|l|l|}
\hline \multicolumn{1}{|c|}{ Kompetensi Dasar Pengetahuan } & \multicolumn{1}{|c|}{ Kompetensi Dasar Keterampilan } \\
\hline $\begin{array}{l}\text { 3.7 Menjelaskan rasio trigonometri (sinus, } \\
\text { kosinus, tangen, kosekan, sekan dan kotangen) } \\
\text { pada segitiga siku-siku. }\end{array}$ & $\begin{array}{l}4.7 \text { Menyelesaikan masalah kontekstual yang } \\
\text { berkaitan dengan rasio trigonometri (sinus, } \\
\text { kosinus, tangen, kosekan, sekan, dan kotangen) }\end{array}$ \\
\hline $\begin{array}{l}\text { 3.8 Menggeneralisasi rasio trigonometri untuk } \\
\text { sudut-sudut di berbagai kuadran dan sudut- } \\
\text { sudut berelasi }\end{array}$ & $\begin{array}{l}4.8 \text { Menyelesaikan masalah kontekstual yang } \\
\text { berkaitan dengan rasio trigonometri sudut-sudut } \\
\text { di berbagai kuadran dan sudut-sudut berelasi. }\end{array}$ \\
\hline $3.9 \quad$ Menjelaskan aturan sinus dan kosinus & $\begin{array}{l}4.9 \text { Menyelesaikan masalah yang berkaitan } \\
\text { dengan aturan sinus dan kosinus }\end{array}$ \\
\hline $\begin{array}{l}\text { 3.10 Menjelaskan fungsi trigonometri dengan } \\
\text { menggunakan lingkaran satuan }\end{array}$ & $\begin{array}{l}4.10 \text { Menganalisa perubahan grafik fungsi } \\
\text { trigonometri akibat perubahan pada konstanta } \\
\text { pada fungsi y=a sin b }(\mathrm{x}+\mathrm{c})+\mathrm{d}\end{array}$ \\
\hline
\end{tabular}

Diadaptasi dari Permendikbud No 24 Tahun 2016

Analisis sarana prasarana yang dilakukan, sekolah memiliki laboratorium komputer dan dapat digunakan untuk mengoperasikan media pembelajaran. Guru menggunakan buku guru sebagai sumber ajar, belum ada media interaktif yang dapat memacu motivasi peserta didik. Dari 12 SMA/SMK di Salatiga, 4 sekolah yang menggunakan media pembelajaran, namun media pembelajaran digunakan hanya materi yang disampaikan sulit jika disampaikan dengan metode ceramah, dan 8 sekolah tidak menggunakan media karena guru menggunakan buku paket/LKS untuk pembelajaran.

Teknologi yang digunakan di sekolah salah satunya adalah komputer. Komputer merupakan sebuah alat teknologi pengolah data yang digunakan oleh semua orang di semua bidang, termasuk bidang pendidikan. Penggunaan komputer untuk pembelajaran dapat menjadikan suasana kelas menjadi menyenangkan dan tidak membosankan. Aplikasi yang sering digunakan dalam pembelajaran adalah PowerPoint. Karena tampilan dalam PowerPoint sangat terbatas, peneliti memperkenalkan AutoPlay Media Studio 8 dalam pembelajaran dengan membuat media pembelajaran bernama Smart Trigo.

\section{Tahap Desain}

Tahap desain merupakan inti dari penelitian pengembangan. Hal yang didesain dalam tahap ini adalah: (1) merancang materi yang akan digunakan, (2) game yang dibuat, (3) tema game, (4) cara kerja media, dan (5) penentuan nama media. Media yang didesain berbasis materi trigonometri karena peserta didik banyak yang kesulitan pada materi ini. Materi meliputi rasio trigonometri, aturan sinus kosinus, dan grafik fungsi trigoonometri.

Aplikasi yang akan digunakan adalah aplikasi software AutoPlay Media Studio. AutoPlay Media Studio merupakan sebuah aplikasi bebas akses yang tidak menggunakan bahasa pemrograman yang rumit. Aplikasi ini bekerja pada Windows XP, Windows 7, ataupun Windows 8. 


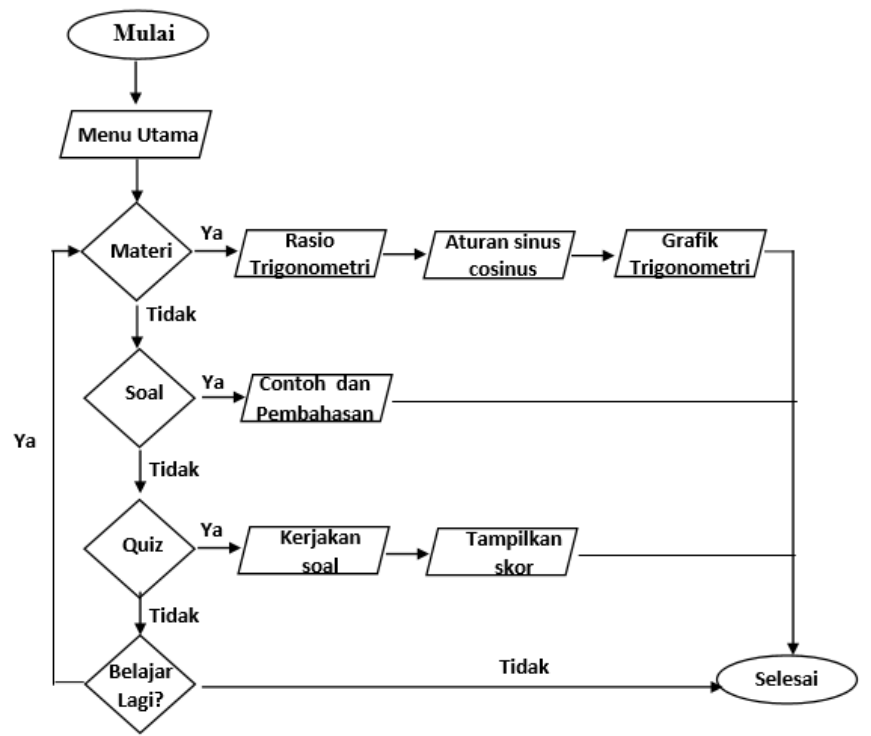

Gambar 2. Bagan proses belajar Smart Trigo

Tampilan pertama terdapat cover Smart Trigo yang terdapat 3 menu, yaitu Materi, Soal dan Quiz. Pada menu Materi terdapat menu Rasio Trigonometri, Aturan Sinus Cosinus dan Grafik. Ketiga menu tersebut dapat dipilih secara acak. Pada saat memilih menu Soal, akan muncul beberapa contoh soal beserta dengan cara pengerjaannya. Jika memilih menu Quiz, akan muncul beberapa soal pilihan ganda untuk dikerjakan dan jika sudah selesai mengerjakan akan muncul nilai. Jika ingin belajar lagi maka akan kembali ke menu Materi, jika tidak ingin belajar lagi maka akan keluar dari aplikasi.

\section{Tahap Pengembangan}

Pada tahap ini peneliti membuat materi ajar dan latihan soal untuk dimasukkan (diinput) ke dalam media. Materi yang dimasukkan ke dalam media diambil dari Buku Guru Matematika Kelas X. Sebelum memasukkan materi ke dalam media, materi divalidasi oleh ahli materi. Selanjutnya membuat Smart Trigo menggunakan AutoPlay Media Studio dan Adobe Flash Player. Smart Trigo berisi materi ajar dan latihan soal trigonometri. Setiap mengerjakan soal latihan, peserta didik dapat mengetahui nilainya. Hasil yang diperoleh dari realisasi berupa multimedia pembelajaran Smart Trigo sebagai berikut :

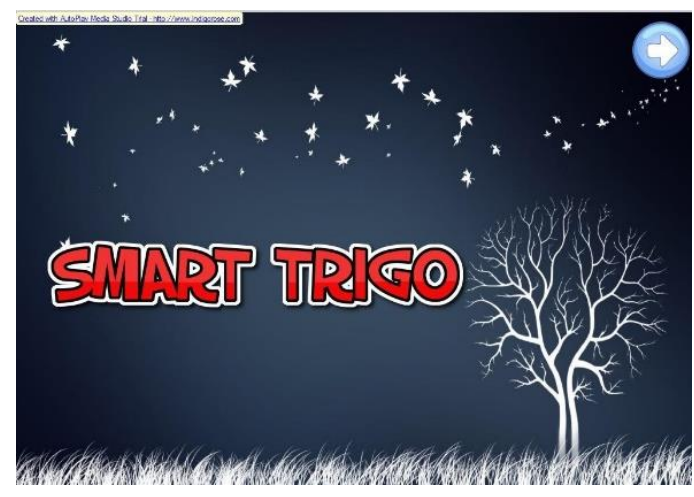

Gambar 3. Tampilan awal sebelum revisi

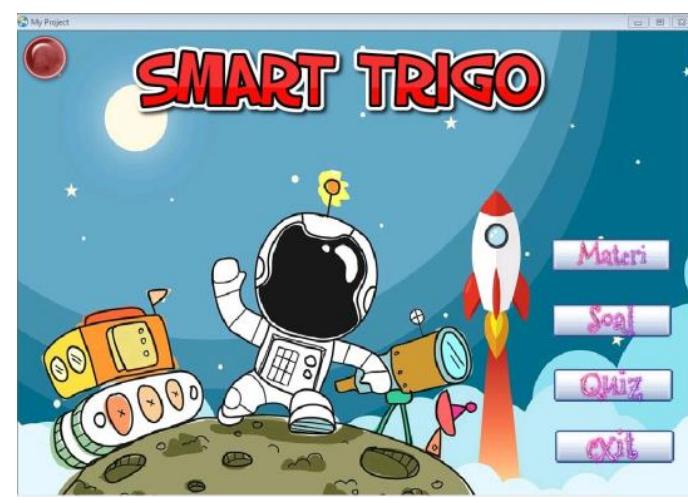

Gambar 4. Tampilan awal sesudah revisi 
Gambar 3 merupakan tampilan awal media sebelum direvisi. Pada Gambar 3, tampilan sangat sederhana. Dan untuk mengetahui menu-menu yang terdapat dalam media, pemain harus menekan tombol Next di pojok kanan layar. Peneliti merevisi background dan tombol-tombol menu. Gambar 4 merupakan tampilan awal media setelah direvisi.

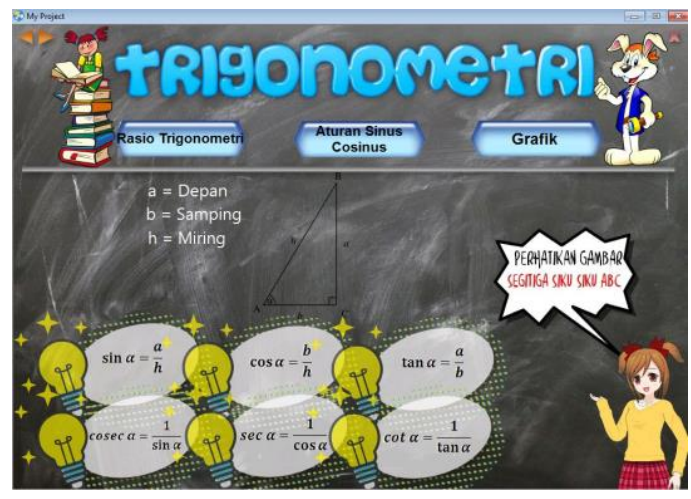

Gambar 5. Tampilan materi sebelum revisi

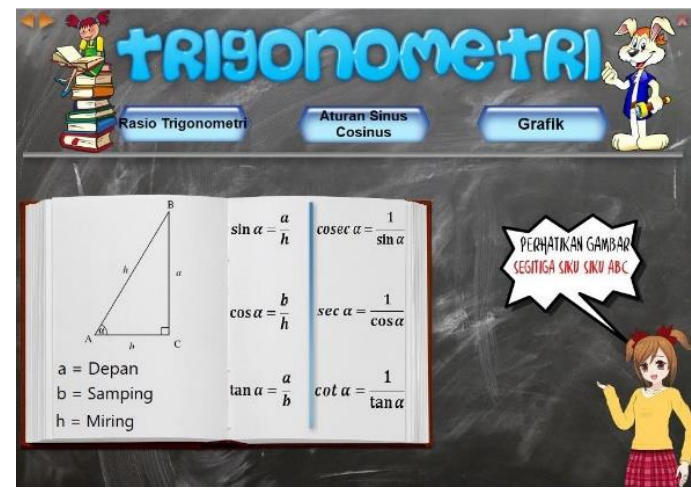

Gambar 6. Tampilan materi sesudah revisi

Jika pemain menekan tombol materi maka akan muncul tampilan seperti Gambar 5 dan Gambar 6. Menu Materi berisi rasio trigonometri, aturan sinus kosinus dan grafik. Di menu materi, pemain dapat belajar trigonometri dasar. Terdapat tombol back dan next di pojok kiri, sehingga pemain dapat mengulang-ulang materi jika tidak paham.

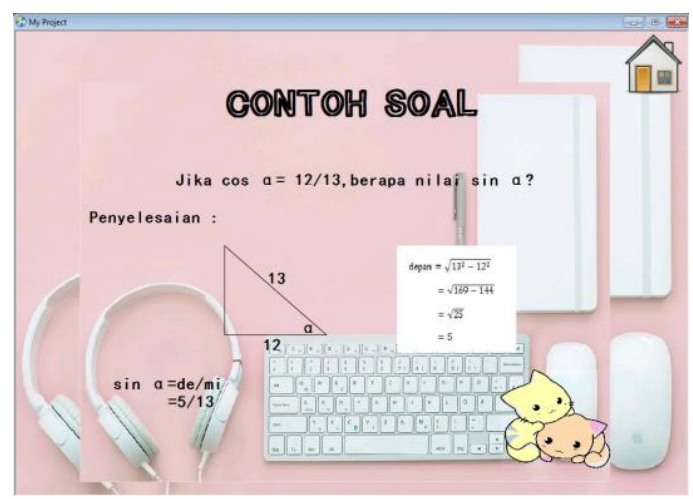

Gambar 7. Tampilan contoh soal

Pada menu Soal terdapat beberapa contoh soal yang dapat ditampilkan seperti Gambar 7. Terdapat tombol "Home" yang akan kembali ke halaman utama jika pemain ingin kembali ke halaman utama. Pada menu Quiz terdapat soal-soal yang harus dikerjakan oleh pemain seperti Gambar 8 dan Gambar 9. Soal quiz berupa soal pilihan ganda, pemain memilih salah satu jawaban yang dianggap benar. Ketika sudah menyelesaikan quiz, pemain akan mengetahui nilai dari quiz tersebut. Selanjutnya dilakukan validasi media yang dilakukan oleh ahli komputer. Hasil dari lembar validasi Smart Trigo oleh ahli media komputer adalah 88,88. Berdasarkan kriteria kevalidan, media pembelajaran layak untuk digunakan yang terlihat pada Tabel 6. 


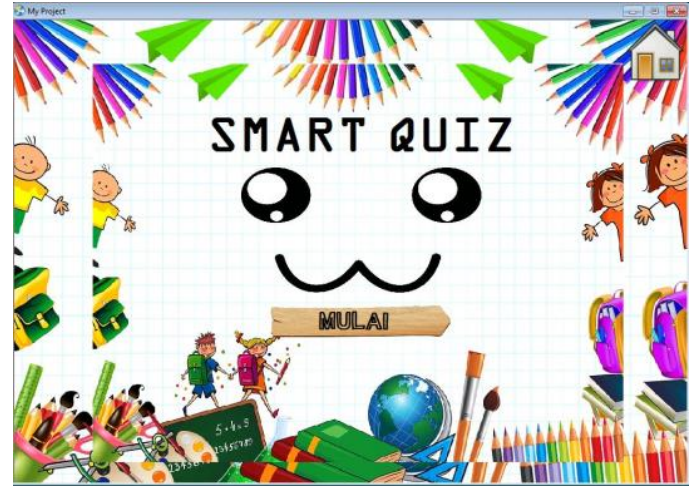

Gambar 8. Tampilan SMART QUIZ

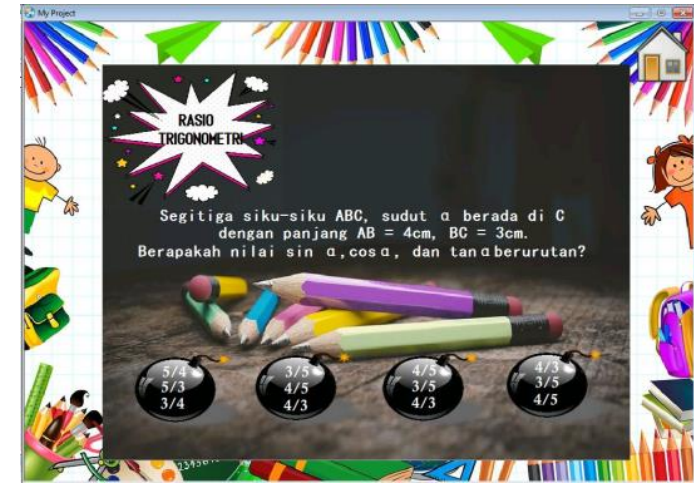

Gambar 9. Tampilan SMART QUIZ

Tabel 6.

Tingkat kevalidan media

\begin{tabular}{|c|c|l|l|}
\hline No & Tingkat Pencapaian & \multicolumn{1}{c|}{ Kualifikasi } & \multicolumn{1}{c|}{ Keterangan } \\
\hline 1 & $81 \%-100 \%$ & Sangat baik & Sangat layak, tidak perlu revisi \\
\hline 2 & $61 \%-80 \%$ & Baik & Layak, tidak perlu revisi \\
\hline 3 & $41 \%-60 \%$ & Cukup baik & Kurang layak, perlu revisi \\
\hline 4 & $21 \%-40 \%$ & Kurang baik & Tidak layak, perlu revisi \\
\hline 5 & $<20 \%$ & Sangat kurang baik & Sangat tidak layak, perlu revisi \\
\hline
\end{tabular}

\section{Tahap Implementasi}

Tahap implementasi dilakukan dengan cara menerapkan media pembelajaran kepada peserta didik yang menjadi subjek penelitian, dimana melibatkan 5 siswa yang sudah mendapatkan materi trigonometri. Dalam penggunaan Smart Trigo, siswa diberi petunjuk penggunaan Smart Trigo. Siswa yang belajar menggunakan Smart Trigo langsung mengerti penggunaan media pembelajaran. Siswa sangat antusias belajar menggunakan Smart Trigo karena menarik dan mudah dipahami. Media Smart Trigo praktis karena membangkitkan motivasi siswa dan merangsang siswa untuk belajar, menghemat waktu dan dapat diputar berulang-ulang.

\section{Tahap Evaluasi}

Berdasarkan hasil angket tentang media Smart Trigo diperoleh siswa setuju animasi yang digunakan dalam Smart Trigo menarik huruf dan warna yang digunakan menarik. Media pembelajaran Smart Trigo mudah digunakan dalam pembelajaran. Media pembelajaran Smart Trigo membantu peserta didik memahami materi trigonometri dan membantu peserta didik dalam pemantapan latihan soal.

\section{Tabel 7.}

Hasil angket siswa

\section{Pendapat/ Saran Siswa}

Media sangat menarik dan mudah digunakan

Dapat ditambah musik agar lebih menyenangkan

Font dapat dibuat lebih menarik

Soal kuis diperbanyak dan dapat diacak agar tidak menghafal jawaban,

Lebih paham jika menggunakan media pembelajaran. 


\section{KESIMPULAN}

Smart Trigo merupakan media pembelajaran matematika untuk materi trigonometri yang dibuat dengan perangkat lunak AutoPlay Media Studio 8. Hasil validasi oleh ahli media dan ahli materi, Smart Trigo layak digunakan. Berdasarkan uji coba skala kecil, belajar menggunakan Smart Trigo memotivasi siswa karena sangat antusias menggunakan media pembelajaran dan memusatkan perhatian ke media tersebut. Media Smart Trigo juga efektif karena mudah dioperasikan, memberikan pembelajaran yang menyenangkan dan membantu dalam memahami konsep yang benar. Berdasarkan hasil pengembangan yang dibuat, diuraikan saran sebagai berikut: (1) guru dapat memanfaatan laboratorium komputer untuk pembelajaran matematika, (2) guru dapat menggunakan aplikasi AutoPlay Media Studio guna menciptakan atau mengembangkan media pembelajaran untuk materi lainnya, (3) menggunakan soal-soal yang bervariasi agar siswa tidak menghafal jawaban dan siswa tidak mudah bosan.

\section{DAFTAR PUSTAKA}

Afrida, Z. (2017). Pengembangan Media Pembelajaran Matematika Berbasis AutoPlay Media Studio Materi Garis dan Sudut Siswa Kelas VII MTs. Ilmu Keguruan Institut Agama Islam Negeri Tulungagung.

Aldoobie, N. (2015). ADDIE Model. American International Journal of Contemporary Research: University Of Colorado.

Arsyad, Azhar. (2016). Media Pembelajaran. Jakarta: Raja Grafindo Persada

Dick, W, Carey, L. Dan Carey, J. O. (2009). The Systematic Design of instruction. Colombus, Ohio: Pearson

Fuad, M. H., \& Srihono. (2019). Pengaruh Media Flip Book Plus Terhadap Hasil Belajar Matematika Siswa Kelas X-IIS SMAN 1 Mejobo Materi Trigonometri Tahun Pelajaran 2018 / 2019. Jurnal Pendidikan Matematika, 1(1), 79.

Jamun, Y. M. (2018). Dampak Teknologi Terhadap Pendidikan. Jurnal Pendidikan Dan Kebudayaan Missio, 10(1), 1-136.

Kemendiknas. (2007). Permendiknas Nomor 16 Tahun 2007 Tentang Standar Kualifikasi Akademik dan Kompetensi Guru, Kompetesi Pedagogik Guru SMA/SMK. Jakarta: Kemendiknas

Kemendikbud. (2016). Permendikbud Nomor 24 Tahun 2016 Tentang Kompetensi Inti Dan Kompetensi Dasar. Jakarta: Kemendikbud

Prasetyo, H., \& Sutopo, W. (2018). Industri 4.0: Telaah Klasifikasi Aspek dan Arah Perkembangan Riset.J@ti Undip: Jurnal Teknik Industri, 13(1), 17-26.

Pribadi, Benny. A. (2009). Model Desain Sistem Pembelajaran. Jakarta: Dian Rakyat.

Rusman. (2012). Model-model Pembelajaran.. Depok: PT Rajagrafindo Persada.

Rusman. (2013). Belajar dan Pembelajaran Berbasis Komputer. Bandung: Alfabeta.

Sugiyono. (2008). Metode Penelitian Kuantitatif Kualitatif dan R\&D. Bandung: Alfabeta. 
Sultoni, A. (2018). Pembelajaran Trigonometri Materi Menentukan Tinggi Suatu Benda Berbantuan Klinometer Fleksibel. Prosiding Seminar Nasional Matematika., 2(1), 860-869.

Rusman. (2013). Belajar dan Pembelajaran Berbasis Komputer.

Utami, D. W., \& Mampouw, H. L. (2018). Pengembangan media pembelajaran Al-Smart untuk Materi Operasi pada Bentuk Aljabar. Prosiding Seminar Nasional Matematika Dan Pendidikan Matematika, 421-427. 